\title{
ALOCAÇÃO EFICIENTE DE INDICADORES DE FALTAS EM UM SISTEMA DE DISTRIBUIÇÃO REAL USANDO COMPUTAÇÃO EVOLUTIVA
}

\author{
Wesley F. Usida* \\ wesleyfulsel.eesc.usp.br \\ Rogério A. Flauzino ${ }^{\dagger}$ \\ raflauzino@sc.usp.br
}

\author{
Denis V. Coury ${ }^{\dagger}$ \\ couryesc.usp.br \\ Ivan N. Silva ${ }^{\dagger}$ \\ insilva@sc.usp.br
}

\author{
*Agência Nacional de Energia Elétrica - ANEEL \\ SGAN 603 Módulo J \\ CEP 70830-030 - Brasília - DF \\ ${ }^{\dagger}$ SEL-EESC-USP São Carlos \\ Av. Trabalhador Sancarlense, 400 Centro \\ CEP 13566-590 - São Carlos - SP
}

\begin{abstract}
Efficient Placement of Fault Indicators in Distribution System using Evolutionary Computing

This work proposes an evolutionary computing strategy to solve the problem of fault indicator placement in primary distribution feeders. The problem is solved using Genetics Algorithm (GA) technique in order to obtain an efficient configuration of fault indicator placement in the main feeder. The results with actual data confirm the efficiency of the GA methodology to solve the fault indicator placement problem. As a result, the distribution reliability indices of quality are improved attending the financial costs.
\end{abstract}

KEYWORDS: Genetic Algorithm, Fault Indicators, Quality of Service, Distribution System.

\section{RESUMO}

Este trabalho propõe uma abordagem computacional evolutiva para a resolução do problema de alocação de dispositi-

Artigo submetido em 29/04/2010 (Id.: 1138)

Revisado em 25/08/2010, 29/12/2010, 28/04/2011, 11/08/2011

Aceito sob recomendação do Editor Associado Prof. Antonio Carlos Zambroni de Souza vos indicadores de faltas (IFs) em alimentadores primários de distribuição de energia elétrica. De forma mais específica, o problema de se obter o melhor local de instalação é solucionado por meio da técnica de Algoritmos Genéticos (AGs) que busca obter uma configuração eficiente de instalação de IFs no tronco principal de um alimentador de distribuição. Assim, faz-se a modelagem do mesmo na forma de um problema de otimização orientado à melhoria dos indicadores de qualidade do serviço e ao encontro de uma solução economicamente atraente. Os resultados com dados reais comprovam a eficiência da metodologia proposta

PALAVRAS-CHAVE: Algoritmos genéticos, Indicadores de faltas, Qualidade do serviço, Distribuição de energia elétrica.

\section{INTRODUÇÃO}

Os desligamentos do sistema de distribuição são causados por uma variedade de eventos como os decorrentes de condições climáticas, de contatos de árvores, de falhas de equipamentos, de acidentes e outros. Esses eventos comprometem a qualidade do fornecimento de energia, pois ocasionam desligamentos não programados aos consumidores. Quando ocorre uma interrupção, localizar o ponto defeituoso é o maior problema encontrado pelas equipes de manuten- 
ção sob orientação dos centros de operação da distribuição, pois o tempo de inspeção requerido pode ser extremamente dispendioso (Baldwin et al., 2001; Baldwin et al., 2003). No entanto, se houver informações sobre a falta, mais rápido será o processo de identificação do ponto defeituoso. Consequentemente, mais ágil será o restabelecimento no fornecimento de energia elétrica (Tang et al., 2000).

Nesse contexto, destaca-se a aplicação de dispositivos indicadores de falta ao processo de detecção do ponto defeituoso, pois estes sinalizam quando pelos mesmos houver a passagem de uma corrente de curto-circuito. Assim, a sua sinalização orienta a equipe de manutenção até o local onde se situa o trecho defeituoso da rede, facilitando o trabalho de isolamento da seção faltosa e a restauração do fornecimento de energia (Muench and Wright, 1984; Falaghi et al., 2005; Zhang et al., 2004).

A aplicação de IFs em redes aéreas de média tensão possibilita às concessionárias de distribuição de energia elétrica melhorar a qualidade do fornecimento aos consumidores, uma vez que esses identificam e sinalizam a ocorrência de curtoscircuitos.

Estudos como os proferidos em Krajnak (2000) apontam que a presença de IFs em pontos estratégicos do sistema de distribuição pode reduzir o tempo de interrupção em até $60 \%$, pois, uma vez que a equipe de manutenção consegue rapidamente localizar a seção faltosa, diminuem-se os índices de desempenho que contabilizam o tempo que o consumidor fica sem energia.

O emprego de técnicas evolutivas para alocação de IFs fora mostrado viável no trabalho apresentado em Cong et al. (2005), no qual os autores realizaram um estudo para posicionamento de IFs em sistemas de distribuição com presença de geração distribuída, utilizando-se técnicas de Algoritmos Genéticos (AGs). Contudo, apesar dos resultados satisfatórios alcançados, a metodologia utilizada não contempla a avaliação do IF do ponto de vista do processo de restabelecimento e também da proximidade de instalação entre esses dispositivos.

Em sistemas de distribuição com centenas ou milhares de pontos, foco do estudo do presente trabalho, é preciso que a alocação seja avaliada para todo o conjunto de IFs que se deseja instalar. Assim, a inserção de um IF no alimentador, ou a sua retirada, deve alterar a localização de todos os outros.

Em de Souza et al. (2008) é proposto um sistema de alocação fundamentado na estimação do potencial de instalação de dispositivos IFs em um sistema de distribuição usando sistemas fuzzy. Foram utilizadas como variáveis do problema de otimização o número de clientes, a carga, a distância da pro- teção e a corrente de curto-circuito mínima para quantificar a potencialidade para instalação de IFs em todos os pontos que compõem o tronco principal de alimentadores de distribuição. Os resultados apresentados pelos autores apenas ordenam os pontos candidatos de acordo com o seu potencial de instalação, não avaliando as configurações de instalação de IFs.

Da literatura correlata ao tema, verifica-se que uma das principais dificuldades encontradas para utilização em larga escala de tais dispositivos está na ausência de metodologias eficientes, que visam apontar quais barras do sistema de distribuição seriam mais apropriadas para instalação dos dispositivos IFs, visando à melhoria da qualidade no fornecimento de energia elétrica. Diante desse contexto, este trabalho propõe a aplicação de técnicas da computação evolutiva, em especial da técnica de Algoritmos Genéticos, para se determinar uma configuração eficiente de instalação de dispositivos IFs no alimentador de distribuição de um sistema real. Para cada configuração encontrada, considerando um número prédefinido de IFs, estimam-se indicadores de qualidade de serviço como também os seus custos financeiros.

$\mathrm{O}$ artigo encontra-se organizado da seguinte forma: logo após esta seção introdutória, estabelece-se a formulação do problema. O sistema elétrico empregado para a validação da técnica proposta é descrito na Seção 3 e a metodologia evolutiva, na Seção 4. Os resultados alcançados são tema da Seção 5 e, por fim, as conclusões são tecidas na Seção 6.

\section{FORMULAÇÃO DO PROBLEMA}

As concessionárias de distribuição visam cada vez mais oferecer aos seus consumidores os melhores índices de qualidade da energia elétrica. No intuito de atender a essas melhorias, muitos investimentos têm sido realizados nas redes primárias, visando à redução do tempo de restabelecimento do sistema. Nesse contexto, o emprego de dispositivos IFs ganhou destaque. Porém, a falta de critérios objetivos tem dificultado o emprego em larga escala desses dispositivos. Sendo assim, busca-se, por meio desta pesquisa, o desenvolvimento inédito de uma metodologia eficiente para posicionamento de IFs no alimentador de distribuição que considere a proximidade dos IFs entre si como também em relação a outros equipamentos com função de indicação de falta.

Para isso, nesta seção é descrita a formulação do problema de alocação dos dispositivos IFs em alimentadores primários de distribuição, como também a metodologia para determinação do tronco principal. 


\subsection{Formulação do Problema de Aloca- ção de IF}

No processo de alocação de IFs é necessária a avaliação das configurações candidatas à instalação desses dispositivos. Esta avaliação deve considerar variáveis do alimentador como a carga, o número de unidades consumidoras e a distância entre equipamentos de proteção com função de indicação de falta e dispositivos indicadores de faltas.

A carga e o número de unidades consumidoras, a jusante da barra do alimentador candidato à instalação de IF, permitem inferir sobre a importância de se ter um dispositivo IF posicionado neste local. Se a jusante da barra, tanto a carga alimentada como o número de unidades consumidoras forem expressivos, este, por sua vez, possuirá um grande potencial de instalação de IF. Por outro lado, caso já exista instalado um dispositivo IF nas proximidades, o potencial, ora tido como elevado, deixa de possuir tanta expressão. Em síntese, o potencial de instalação decai para barras próximas a outros dispositivos IF. O mesmo se faz para pontos onde há dispositivos de proteção com função semelhante ao dispositivo IF como, por exemplo, disjuntores, religadores de distribuição e seccionadores automáticos.

Para a definição de uma expressão matemática que avalie as configurações candidatas à instalação de IFs, foram necessários diversos estudos com as variáveis mencionadas anteriormente no intuito de se verificar o seu inter- relacionamento com o problema de alocação dos IFs. Uma boa estratégia para representar tal relacionamento pode ser expressa pela área sob a curva resultante da composição das variáveis: distância de cada barra ao dispositivo mais próximo com função de indicação de falta, carga e número de unidades consumidoras situados no tronco principal. A expressão matemática que representa o problema de alocação é expressa como:

$$
f(x, y, z)=\sum_{i=1}^{n} x_{i}+y_{i} z_{i}
$$

Em que:

- $x$ é a variável carga acumulada a jusante da barra avaliada;

- y é o número de unidades consumidoras acumulado referente à barra avaliada pertencente ao tronco principal;

- $z$ é a representação da distância de cada barra ao mais próximo elemento de indicação de falta;

- $n$ representa o número de barras que compõem o tronco principal.
As variáveis carga e número de unidades consumidoras representadas pela Eq. (1) foram modeladas por meio de uma soma com mesma ponderação. Isto foi adotado, pois estudos mais aprofundados com tais variáveis não foram possíveis de serem realizados por falta de informações mais detalhadas das cargas e das unidades consumidoras. Já a variável distância foi empregada para garantir que os pontos a serem instalados IFs não estivessem próximos de dispositivos de proteção ou entre si. Ao mesmo tempo, a expressão (1) fornece informações sobre a densidade de carga e das unidades consumidoras e sobre a distância supracitada. A área mencionada anteriormente é composta por sub-regiões, compreendidas entre os equipamentos de proteção e/ou IFs, que serão percorridas pelas equipes de manutenção.

Com isso, a configuração de instalação de dispositivos IFs que proporcionar a menor área sob a curva resultante da expressão (1) representará a solução eficiente de alocação de IFs. Portanto, o problema de alocação dos IFs pode ser denotada pela expressão:

$$
\text { Minimizar } \quad \sum_{i=1}^{n} x_{i}+y_{i} z_{i}
$$

A variável $z$ deve ser calculada a cada configuração candidata à instalação de IFs. Este processo é necessário para se verificar a proximidade dos IFs candidatos tanto entre si como também em relação aos dispositivos de proteção com seccionamento tripolar e função de indicação de faltas.

\subsection{Determinação do Tronco Principal}

Para fins de análise e de aplicações práticas, há de se considerar, ainda, o posicionamento de IFs apenas no tronco principal que é o responsável por atender todas as cargas do alimentador. Essa consideração se justifica, pois, diante da interrupção do fornecimento de energia elétrica desencadeada por uma falta, o restabelecimento do serviço poderá ser feito gradualmente conforme as equipes de manutenção percorram o tronco principal e verifiquem que a barra defeituosa está a montante ou a jusante do último IF inspecionado. No entanto, para um sistema de distribuição grande e com várias ramificações, a determinação do ramo principal pode ser laboriosa (de Souza et al., 2008). Para a obtenção dos trechos que compõem o tronco principal do alimentador considerar-se-á, inicialmente, o diagrama unifilar de um sistema de distribuição de 13 barras como ilustrado pela Figura 1 (Kersting, 1991).

A determinação do tronco principal não é realizada de forma direta, requerendo o cálculo da distância de cada barra em relação à subestação. Esse cálculo torna-se essencial, pois 
se necessita encontrar o barramento mais distante da subestação. Por meio desse princípio, o conjunto de trechos primários que conduzir, a partir da subestação, à barra mais distante da mesma, constituir- se-á o tronco principal do alimentador. Assim, considerando-se os comprimentos dos trechos primários indicados na Figura 1, tem-se o sistema de equações lineares registrado em (3).

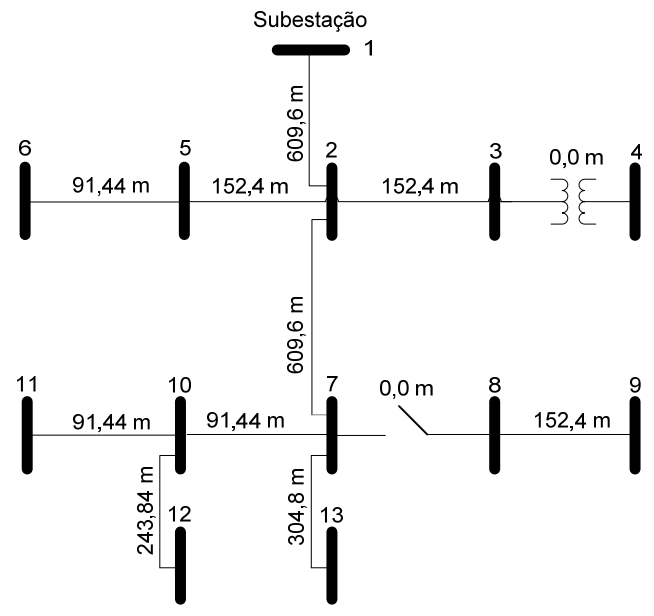

Figura 1: llustração do sistema de distribuição visando à obtenção do tronco principal.

$$
\left\{\begin{aligned}
x_{1} & =0 \\
x_{1,2} & =x_{2}-x_{1}=609,60 \\
x_{2,3} & =x_{3}-x_{2}=152,40 \\
x_{3,4} & =x_{3}-x_{4}=0 \\
x_{2,5} & =x_{5}-x_{2}=152,40 \\
x_{5,6} & =x_{6}-x_{5}=91,44 \\
x_{2,7} & =x_{7}-x_{2}=609,60 \\
x_{7,8} & =x_{8}-x_{7}=0 \\
x_{8,9} & =x_{9}-x_{8}=152,40 \\
x_{7,10} & =x_{10}-x_{7}=91,44 \\
x_{10,11} & =x_{11}-x_{10}=91,44 \\
x_{10,12} & =x_{12}-x_{10}=243,84 \\
x_{7,13} & =x_{13}-x_{7}=304,80
\end{aligned}\right.
$$

Expressando (3) em forma matricial, tem-se:

$$
A x=b
$$

onde: onde $x_{i}$ representa a distância, em relação à subestação, da i-ésima barra do sistema de energia elétrica. Supondo um típico sistema de distribuição radial, é possível afirmar que não existirá redundância de caminhos para uma mesma barra. Assim, dado um sistema com $n$ barras, haverá então $(n-1)$ equações de trechos primários para determinação da distância das barras até a subestação. Somando- se a esse conjunto de equações a referência de distância nula para a barra repre- sentativa da subestação totalizar-se-á $n$ equações. Face ao exposto, torna-se possível afirmar que a matriz $A$ será quadrada quando se referir a sistemas de energia inteiramente radiais, tais como os de distribuição. Em função dessa constatação, a solução de (4) pode ser obtida da seguinte maneira: 


$$
x=A^{-1} b
$$

Para o exemplo abordado, a matriz $A^{-1}$ pode ser expressa em (8). Consequientemente, o vetor de distâncias $x$ é dado por:

$$
A^{-1}=\left(\begin{array}{cccccccc}
1 & & & & & & & \\
1 & 1 & & & & & & \\
1 & 1 & 1 & & & & & \\
1 & 1 & 1 & 1 & & & & \\
1 & 1 & & & 1 & & & \\
1 & 1 & & & 1 & 1 & & \\
1 & 1 & & & & & 1 & \\
1 & 1 & & & & 1 & 1 \\
1 & 1 & & & & 1 & 1 \\
1 & 1 & & & & & 1 & \\
1 & 1 & & & & & 1 & \\
1 & 1 & & & & 1 & \\
1 & 1 & & & & & 1 &
\end{array}\right.
$$

Verifica-se que a barra que está mais distante da subestação é aquela de número 12 , posicionando-se a $1554,48 \mathrm{~m}$ da subestação representada pela barra de número 1 . Retomando-se à matriz $A^{-1}$, tem-se que a linha correspondente à barra mais distante é constituída da seguinte forma:

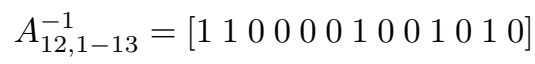

Lembrando-se de que as linhas de $A$ foram constituídas pelo conjunto de equações expresso em (3), a mesma inferência pode ser feita para as colunas de $A^{-1}$. Portanto, os conjuntos de trechos primários que constituem o tronco principal são aqueles entre as barras 1 e 2,2 e 7,7 e 10 , e as barras 10 e 12. A Figura 2 ilustra o tronco principal do alimentador empregado como exemplo.

Assim, visando à formulação do método proposto, nas seções seguintes será apresentado como as variáveis consideradas relevantes para o problema de alocação de dispositivos IF se comportam ao longo do tronco principal (de Souza et al., 2008).

Para validar a metodologia proposta foi investigado o posicionamento de IFs em um alimentador de distribuição real como descrito na seção a seguir.

\section{O SISTEMA ELÉTRICO ESTUDADO}

Para os estudos relatados neste trabalho, utilizou-se um alimentador real de distribuição, conforme ilustrado pela Fig. 3. Foram consideradas informações desse alimentador,

$$
\left.\begin{array}{cccc} 
& & & \\
& & & \\
& & & \\
& & & \\
& & & \\
& & & \\
& & & \\
& & & \\
1 & & & \\
1 & 1 & & \\
1 & & 1 & \\
& & & 1
\end{array}\right), x=\left(\begin{array}{c} 
\\
762,00 \\
762,00 \\
762,00 \\
853,44 \\
1219,20 \\
1219,20 \\
1371,60 \\
1310,64 \\
1402,08 \\
1554,48 \\
1524,00
\end{array}\right)
$$

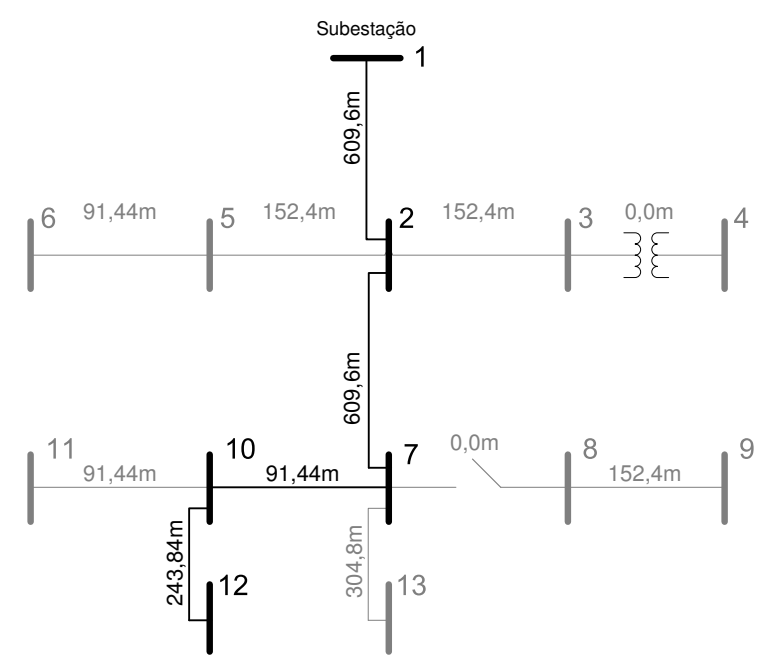

Figura 2: Sistema de distribuição com destaque para o tronco principal.

tais como: o número de unidades consumidoras, a carga instalada, coordenadas geográficas, o tipo e a localização dos equipamentos de proteção. Esse alimentador foi escolhido por possuir cargas urbanas e rurais. $\mathrm{O}$ fato do alimentador possuir clientes em região rural faz com que ele possua grande parte de sua extensão em região também rural. Essa característica é sabidamente fator comprometedor do tempo de atendimento às ocorrências, devido às grandes distâncias a serem percorridas na busca do local com defeito. Assim, a instalação de IFs em alimentadores resulta em melhorias dos tempos envolvidos com o restabelecimento do sistema 


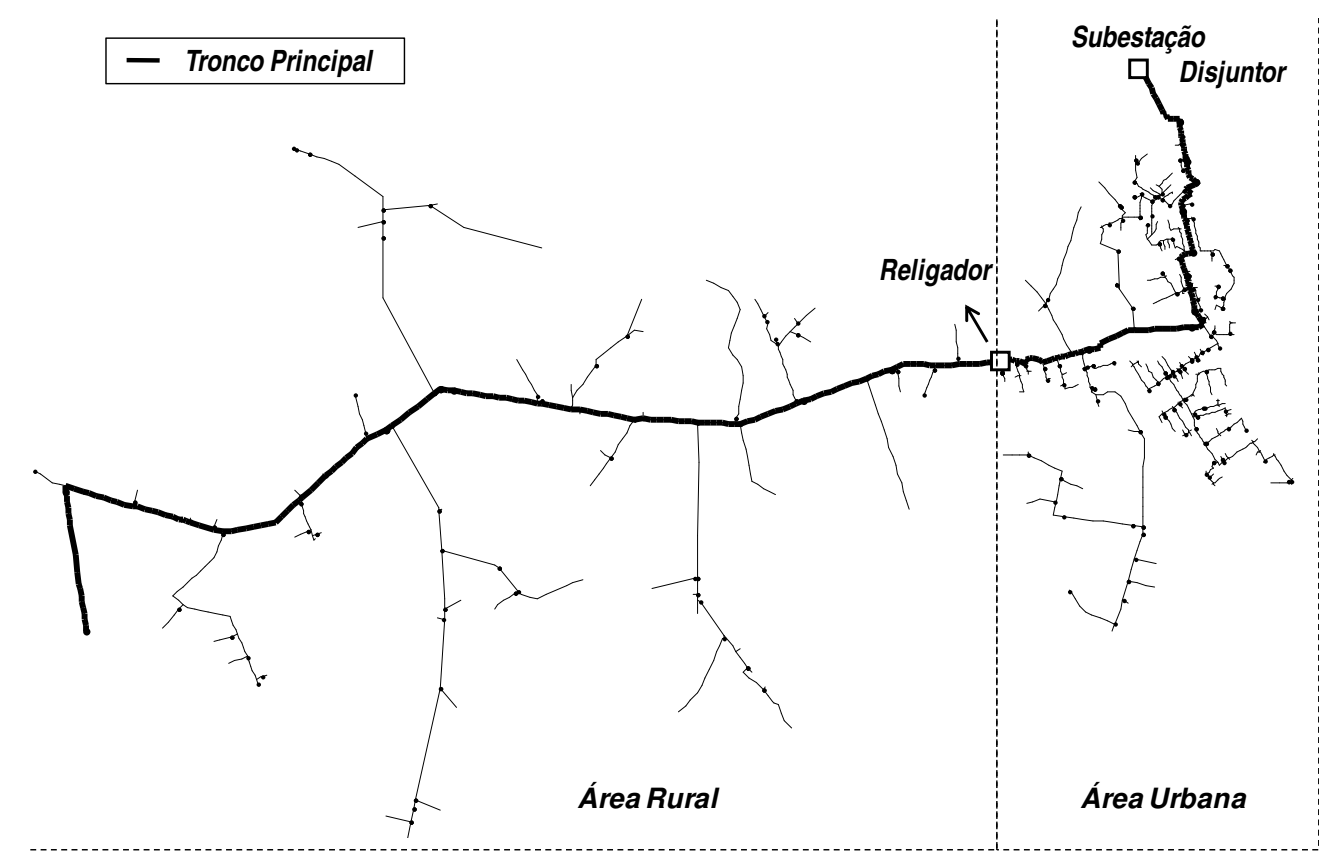

Figura 3: Alimentador estudado destacando o tronco principal.

de distribuição, pois auxiliam as equipes de inspeção na localização do trecho defeituoso de forma mais rápida.

Com o objetivo de apresentar maiores detalhes acerca do alimentador investigado, apresenta-se a seguir os parâmetros desse sistema elétrico:

- Tronco principal com $18,39 \mathrm{~km}$.

- 2002 barras;

- 2001 trechos de rede primária em 13,8 kV;

- 5480 unidades consumidoras sendo 5341 urbanas e 139 rurais;

- Carga instalada de 16,02 MVA;

- Dois dispositivos de proteção com função de indicação de falta e manobra tripolar, onde o primeiro é o disjuntor do alimentador na subestação e o segundo é uma chave religadora instalada a $5,79 \mathrm{~km}$ da subestação.

No alimentador primário de distribuição existem diversos pontos nos quais os IFs podem ser instalados. Como já enfatizado anteriormente, neste trabalho considerou-se apenas a instalação de IFs no tronco principal, pois o mesmo é responsável por atender todas as cargas do alimentador. Além disso, a inspeção em busca de pontos defeituosos deve ocorrer primeiramente no tronco principal.
Para isso foram considerados, no tronco principal, aspectos como número de unidades consumidoras que podem ser afetadas na ocorrência de um desligamento, a carga instalada no ponto e a distância entre dispositivos utilizados na localização da seção faltosa.

Como há diversas cargas ligadas nos circuitos ramais do alimentador de distribuição, estas foram agrupadas por ramal como uma carga equivalente conectada ao tronco principal. Assim, o comportamento da carga ao longo do tronco principal pode ser conferido pela Fig. 4 .

De forma similar, considerou-se o valor acumulado de unidades consumidoras conectadas a cada circuito ramal e atribuído este montante de consumidores ao ponto no qual o circuito ramal está conectado no tronco principal. O comportamento do número de unidades consumidoras pode ser conferido pela Fig. 5.

Por outro lado, se os pontos escolhidos, avaliados apenas pelos critérios de carga e número de unidades consumidoras, estiverem muito próximos de pontos que já possuem IFs instalados ou de equipamentos de proteção com função semelhante aos IFs, o potencial do ponto deixa de ter tanta importância. Estes equipamentos de proteção têm grande importância no processo de identificação de uma falta permanente e, conseqüentemente, no processo de restabelecimento de energia, pois, além de possuírem a função de proteção do sistema, também indicam a passagem de uma corrente de falta permanente pelo ponto que estão instalados. Com 


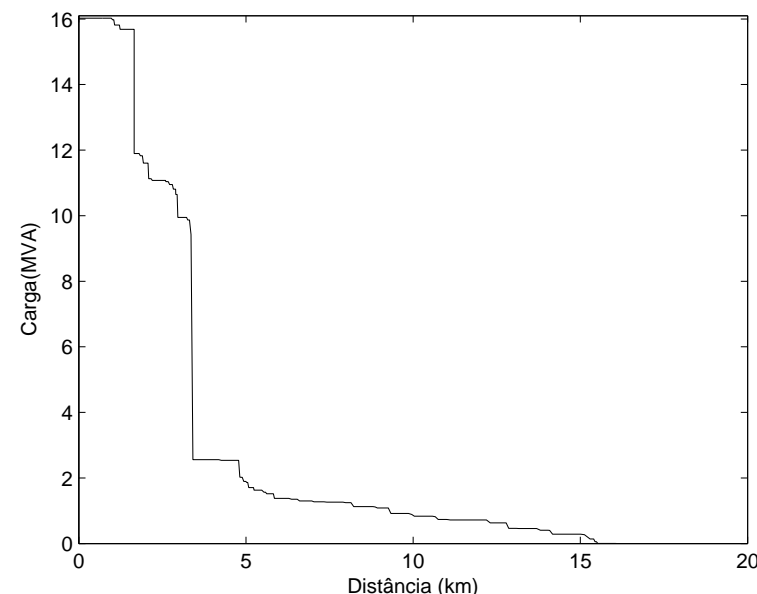

Figura 4: Comportamento da carga ao longo do tronco principal.

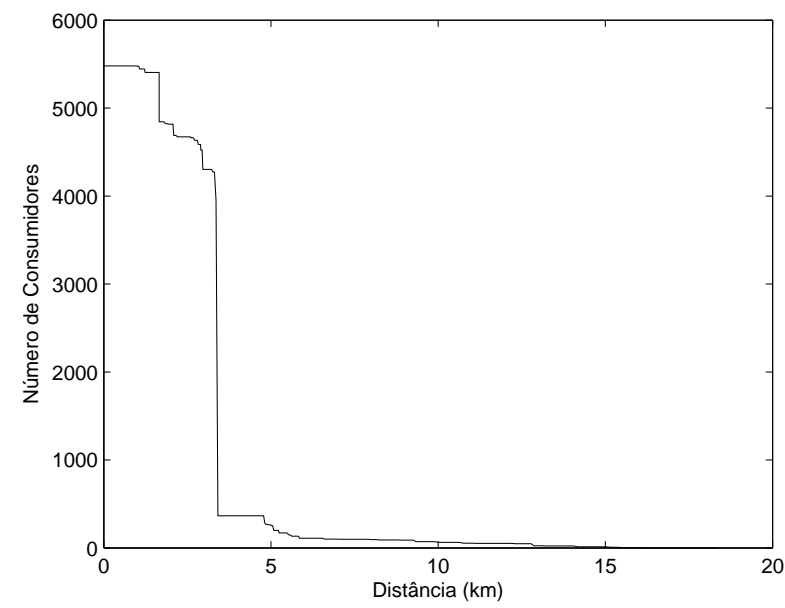

Figura 5: Comportamento do número de unidades consumidoras ao longo do tronco principal.

isso, torna-se importante verificar a distância de cada barra do tronco principal ao dispositivo IF ou semelhante mais próximo.

Observa-se pela Fig. 6, que as barras entre a subestação e o religador possuem menor distância em relação ao dispositivo com função de indicação de falta mais próximo, quando comparado com uma situação sem a presença de IF no tronco principal. Tal análise aponta que a inserção de IFs na rede elétrica modifica o valor da distância de cada barra, impactando no tamanho dos trechos que as equipes terão de percorrer ao longo do tronco para encontrar o ponto defeituoso. Com isso, pode-se afirmar que os IFs devem ser instalados em pontos do tronco principal onde minimizem essa distân- cia, ou seja, a área da região sob a curva que representa o comportamento das distâncias supracitadas.

A aplicação da expressão (2) para uma configuração sem IFs no tronco principal resulta no gráfico ilustrado pela Fig. 7. De forma análoga para a instalação de um IF em uma barra situada no tronco principal a 2,47 km da subestação, tem-se o gráfico ilustrado pela Fig. 8. Por meio da análise da área sob a curva dessas figuras determinou-se que a área mínima resultante de uma determinada configuração de instalação de IFs seria a resposta mais eficiente. Tal área representa as sub-regiões compreendidas entre equipamento de proteção e/ou IFs que as equipes de manutenção percorrerão. Quanto menor forem essas sub-regiões mais eficiente será o posicionamento dos IFs para o processo de busca pelas equipes de manutenção na busca do ponto defeituoso. Cabe ressaltar que sempre foi considerado nas análises um número pré-definido de dispositivos que se deseje instalar.

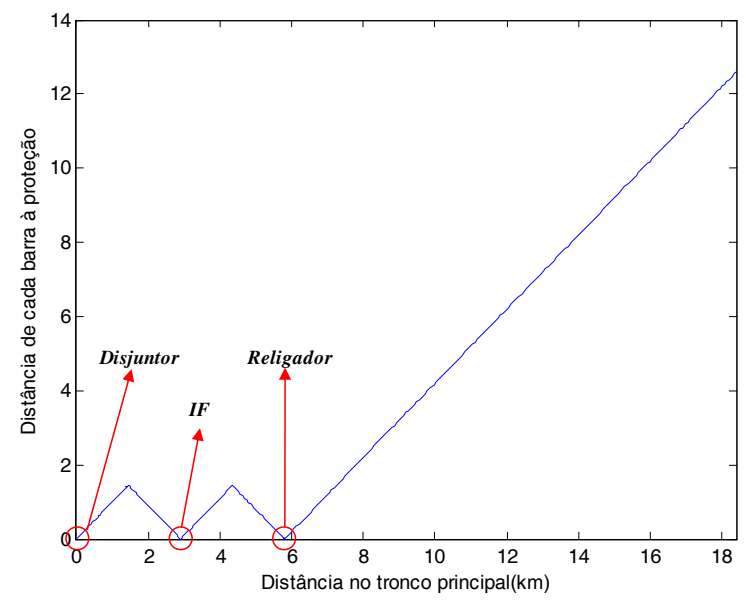

Figura 6: Comportamento da distância de cada barra do tronco principal em relação ao mais próximo dispositivo com função de indicação de falta.

\section{METODOLOGIA DESENVOLVIDA}

O problema de alocação dos dispositivos IFs é combinatorial, pois há inúmeras configurações de instalação de IFs que devem ser avaliadas. É possível verificar que existem algumas técnicas que podem ser utilizadas para a resolução do problema de alocação dos dispositivos IFs. Diante disso, duas técnicas foram estudadas para atender aos propósitos da pesquisa.

Um dos caminhos estudados para resolução do problema de alocação de IFs é por meio da técnica de busca exaustiva que consiste em uma estratégia de força bruta na qual todas as possibilidades de instalação de IF são avaliadas. Entre- 


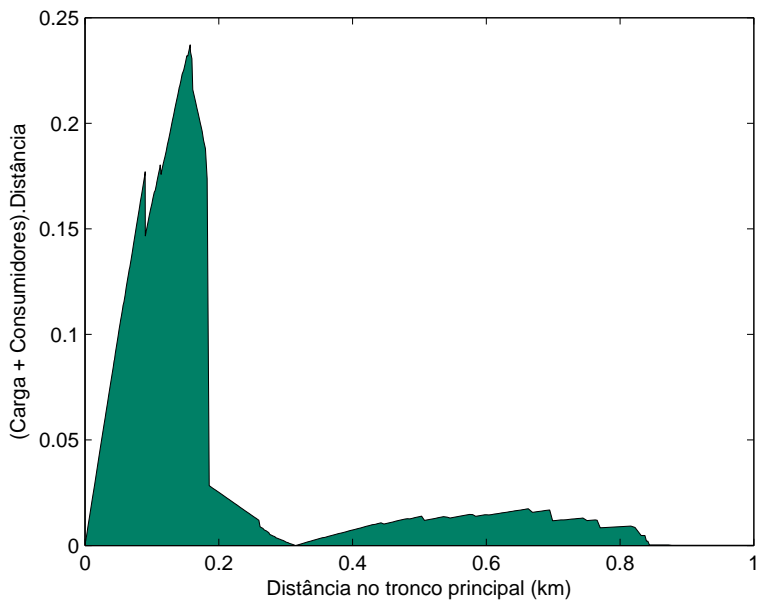

Figura 7: Área sob a curva sem a presença de IF.

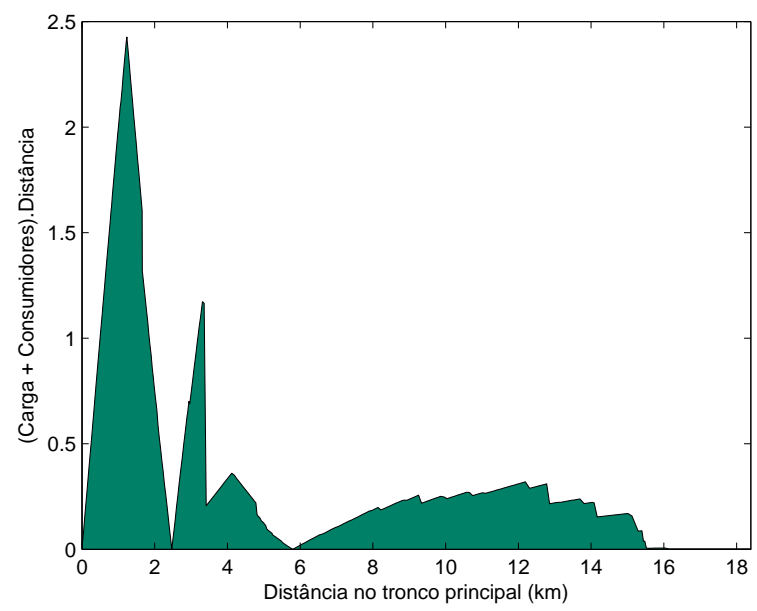

Figura 8: Área sob a curva obtida para 1 IF instalado.

tanto, a aplicação de tal estratégia foi uma solução que requereu elevado esforço computacional, inviabilizando o seu emprego para o problema estudado nesta pesquisa, pois o espaço de busca para algumas situações é muito grande. Citase, como exemplo, a instalação de 4 IFs em 336 barras do tronco principal que totaliza aproximadamente 521 milhões de combinações possíveis de instalação.

Uma ampla avaliação de todas as estratégias encontradas na literatura demonstrou que a maioria delas não contemplou a influência das configurações de IFs com a localização dos equipamentos de proteção, conforme citados na seção 3. Assim, os resultados alcançados apresentavam pontos à instalação de IFs próximos entre si ou de equipamentos de proteção. Esses estudos motivaram ainda mais a busca por uma ferra- menta inteligente que possa encontrar uma configuração eficiente de pontos do tronco principal à instalação de IFs. Para tanto, foi utilizada a técnica de Algoritmos Genéticos devido a sua facilidade de implementação e robustez na resolução de diversos tipos de problemas, sobretudo os de natureza combinatória. Aspectos mais detalhados do algoritmo computacional fundamentado em AG são apresentados na subseção a seguir.

\subsection{Algoritmo Genético Empregado na Alocação de IFs}

A Fig. 9 apresenta o fluxograma de execução do método proposto.

Primeiramente, define-se a quantidade de dispositivos que se deseje instalar. Após essa etapa, gera-se a população inicial de forma aleatória. Para cada indivíduo dessa população é avaliada sua aptidão por meio da função objetivo expressa pela Equação (2). Na etapa de elitismo, o(s) melhor(es) indivíduos são selecionados e inseridos para integrar a população da próxima geração. Os demais indivíduos da população passam pelo processo de seleção, no qual são escolhidos os indivíduos para a etapa de cruzamento. Dessa última, filhos são gerados e alguns deles sofrem mutação. Estes novos indivíduos são inseridos na população da próxima geração. Se o critério de parada por número máximo de gerações é satisfeito, encerra-se o processo de busca. Caso contrário, o processo é repetido desde a etapa de avaliação dos candidatos. Ao final de todo processo relativo ao AG, o indivíduo mais adaptado da população final representa a solução referente à configuração eficiente de instalação de IFs.

Em um mecanismo baseado em AGs, cada indivíduo da população deve representar uma possível solução do problema tratado. Em outras palavras, deve-se fazer uma representação da solução candidata por meio de uma cadeia de genes. Investigou-se a codificação dos indivíduos por meio da representação binária, como proposta por Cong et al. (2005). Porém, essa estratégia não se enquadrou no problema pesquisado neste trabalho, pois o número de pontos candidatos à instalação de IFs é muito superior ao estudado por Cong et al. (2005).

No trabalho de pesquisa aqui proposto são 336 pontos candidatos à instalação de IFs no tronco principal, totalizando $2^{336}$ possibilidades de configuração para a instalação de IFs. Portanto, o emprego da técnica de AG com representação binária não produziu bons resultados e, ainda, exigiu elevado tempo de processamento computacional. Diante da ineficiência da codificação binária, optou-se por uma codificação inteira referente aos pontos candidatos à instalação de IFs no tronco principal, como ilustrada na Fig. 10. 


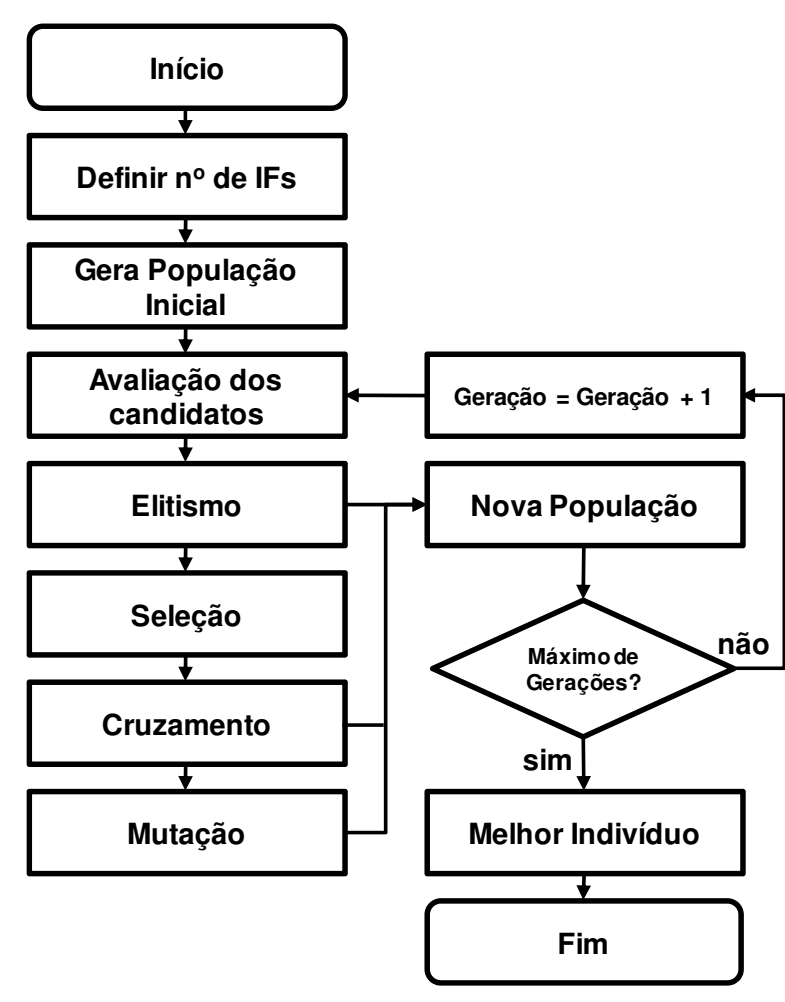

Figura 9: Fluxograma do algoritmo genético desenvolvido.

Indivíduo \begin{tabular}{c|c|c|c|c|c|}
\hline $\begin{array}{c}\text { Barra } \\
5\end{array}$ & $\begin{array}{c}\text { Barra } \\
16\end{array}$ & $\begin{array}{c}\text { Barra } \\
24\end{array}$ & $\begin{array}{c}\text { Barra } \\
135\end{array}$ & $\ldots$ & $\begin{array}{c}\text { Barra } \\
214\end{array}$ \\
\hline 1 & 2 & 3 & 4 & $\ldots$ & $n$
\end{tabular}

Figura 10: Codificação de um indivíduo.

Por meio da Fig. 10, observa-se exemplo de um indivíduo codificado. Verifica-se que cada indivíduo possui os seus genes numerados de 1 a $n$ representando as posições do tronco principal candidatas à instalação dos IFs. O valor de $n$ é definido pelo número de dispositivos IF que se deseja instalar.

Cada indivíduo representa apenas uma possível resposta. Assim o indivíduo formado por [ $\left[\begin{array}{llllll}5 & 16 & 24 & 135 & \ldots\end{array}\right.$ 214 $]$ só poderá ser considerado eficiente se, ao final de todo o processo de otimização relacionado aos AGs, for considerado o mais adaptado. Esta avaliação é feita pela função objetivo que avalia as diversas variáveis envolvidas no problema, conforme expressão (2).

No cruzamento empregou-se a estratégia proposta por Haupt and Haupt (2004), conforme ilustra a equação (10).

Individuo $_{\text {novo }}=\alpha$ Individuo $_{\text {pai }}+(1-\alpha)$ Individuo $_{\text {mãe }}$ onde $\alpha$ representa um número aleatório no intervalo $[0,1]$.

Também foi empregado no processo de mutação o método descrito por Haupt and Haupt (2004), conforme apresentado pela expressão (11).

$$
\mathrm{Gene}_{i}^{\text {novo }}=\text { Gene }_{i}^{\text {atual }}+\sigma N(0,1)
$$

onde $i$ representa o gene que irá sofrer a mutação; $\sigma$ representa o desvio padrão de uma distribuição normal; $N$, a distribuição normal com média 0 e variância igual a 1 .

Os operadores de cruzamento e mutação descritos em Haupt and Haupt (2004) são comumente aplicados em variáveis contínuas, apesar dos cromossomos serem codificados por meio da representação inteira. Como conseqüência, a aplicação desses operadores genéticos poderia resultar genes representados por números reais. Nestes casos, o gene foi aproximado para um número inteiro. Em resumo, os operadores genéticos foram adaptados de forma a atender os indivíduos por representação inteira.

\subsection{Avaliação do Posicionamento dos IFs}

O algoritmo apresentado na Fig. 9 retorna à configuração mais eficiente para o posicionamento de IFs no alimentador principal, mediante uma quantidade de dispositivos pré- definidos que se deseje instalar. Porém, o número de IFs a serem instalados é finito, de modo que é preciso avaliar se a configuração obtida com AGs proporciona benefícios interessantes para a melhoria do tempo de restabelecimento, atendimento às metas de indicadores de continuidade e os recursos financeiros disponíveis.

O tempo de restabelecimento é formado em sua maior parte pelo tempo despendido pela equipe de manutenção na localização do ponto defeituoso, que pode ser melhorado com a presença de IFs na rede de distribuição. É possível estimar o tempo médio gasto pelas equipes de plantão para percorrer o alimentador com ou sem dispositivos que sinalizam faltas. $\mathrm{Na}$ Fig. 11 tem-se um exemplo de um tronco principal com tais dispositivos: 1 IF e 1 Religador de distribuição (RL). Para tal cenário, é possível dividir o alimentador em trechos que serão inspecionados em uma situação de falta.

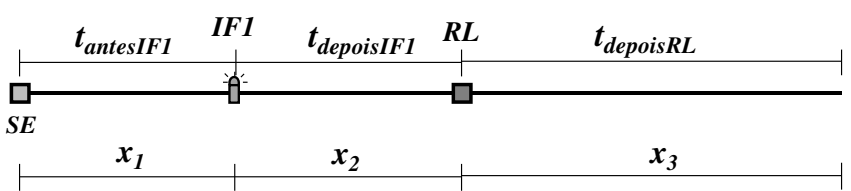

Figura 11: Divisão do tronco em trechos de inspeção. 
As distâncias de cada trecho são conhecidas. Assim a distância total é dada pela soma das mesmas. Para o exemplo da Fig. 11, tem-se a distância total expressa pela equação (12). O tempo de inspeção para percorrer cada trecho será o comprimento do mesmo em relação ao total do alimentador, multiplicado pelo tempo total para se percorrer o alimentador, conforme ilustra a equação (13):

$$
\begin{aligned}
x_{\text {total }} & =x_{1}+x_{2}+x_{3} \\
t_{\text {antes IFI }} & =\left(\frac{x_{1}}{x_{\text {total }}}\right) x_{\text {total }}
\end{aligned}
$$

onde $x_{\text {total }}$ é o comprimento do tronco principal, $x_{1}, x_{2}$ e $x_{3}$ representam o comprimento dos trechos mencionados e $t_{\text {total }}$ é o tempo médio de inspeção para percorrer toda a extensão do tronco principal.

Expandindo-se o raciocínio para os demais trechos, têm-se os tempos para percorrer os trechos $x_{2}$ e $x_{3}$, conforme ilustram as expressões (14) e (15):

$$
\begin{aligned}
t_{\text {depois IFI }} & =\left(\frac{x_{2}}{x_{\text {total }}}\right) x_{\text {total }} \\
t_{\text {depois } R L} & =\left(\frac{x_{3}}{x_{\text {total }}}\right) x_{\text {total }}
\end{aligned}
$$

O tempo médio de inspeção do alimentador com a presença de dispositivos IFs é obtido por meio da média aritmética dos tempos despendidos pelas equipes de plantão para percorrer cada trecho. Supondo um tempo fixo para inspecionar o alimentador sem dispositivos indicadores, tem-se a relação de tempo de inspeção médio por unidade de comprimento do alimentador e, assim, pode-se relacioná-lo com o tempo para percorrer cada trecho.

Esta metodologia pode ser extrapolada para quaisquer quantidades de IFs que se deseja instalar no alimentador primário. Adicionalmente, é possível averiguar qual é a melhoria do tempo médio despendido pelas equipes de plantão para encontrar o ponto defeituoso, à medida que mais dispositivos são instalados. Este raciocínio fornece subsídios para os projetistas avaliarem o custo/benefício da instalação das melhores configurações dos IFs sugeridos pelo AG. Diante disto, é necessário fazer uma estimativa do impacto destes tempos nos indicadores de continuidade e também nos custos financeiros agregados ao emprego dos IFs.

\subsection{Estimação dos Indicadores de Quali- dade do Serviço}

Para avaliar as configurações de IFs a serem instaladas ao longo do tronco principal, é necessário estimar os índices de qualidade de serviço com a presença do(s) IF(s) posicionado(s) pelos AGs. Este tipo de estimação contribui para verificar se o alimentador de distribuição atende às metas de qualidade de serviço a serem alcançadas pela concessionária, conforme estabelecido pela ANEEL (2009). A metodologia de estimação dos indicadores de continuidade do serviço devido a interrupções não programadas, empregada neste trabalho, é fundamentada em (Kagan et al., 2005; Kagan et al., 2009). Outro importante parâmetro a ser estimado é a Energia Não Distribuída (END). Esta refere-se à energia não fornecida aos consumidores devido a um desligamento não programado.

As expressões (16) e (17) determinam as estimativas de DEC e END como apresentado em (Kagan et al., 2005; Kagan et al., 2009):

- Duração equivalente de interrupção por unidade consumidora (DEC $\left.C_{\text {estimado }}\right)$ :

$$
D E C_{\text {estimado }}=\sum_{i=1}^{n_{\text {trechos }}}\left(f_{f} t_{f} x_{i} \frac{N_{a}}{N_{c}} t_{i}\right)
$$

onde $f_{f}$ é o fator de falhas permanentes, $t_{f}$ é a taxa de falhas por ano e por quilômetro $(\mathrm{km}), x_{i}$ é o comprimento de cada trecho em $\mathrm{km}, N_{a}$ representa o número de unidades consumidoras afetadas pelo desligamento referente ao trecho avaliado, $N_{c}$ é o número total de unidades consumidoras supridas pelo alimentador em análise e $t_{i}$ representa a estimativa de tempo que os consumidores ficaram sem fornecimento de energia sendo composto pelo tempo de atendimento dos centros de operação e acionamento da equipe de plantão acrescido pelo tempo médio de inspeção, conforme apresentados na seção 4.2, e, por fim, pelo tempo de reparo e restabelecimento do sistema.

- Energia não distribuída $\left(E N D_{\text {estimado }}\right)$ - corresponde à energia não fornecida aos consumidores de um sistema, durante um período de análise.

$$
E N D_{\text {estimado }}=\sum_{i=1}^{n_{\text {trechos }}} f_{f} t_{f} D_{i} t_{i}
$$

onde $D_{i}$ é a demanda média anual.

Conforme apresentado em Kagan et al. (2009), a taxa de falhas de um dado equipamento da rede elétrica corresponde a 
uma informação para se determinar os indicadores de continuidade de serviço. Este parâmetro, para o caso de trechos de rede, representa o número médio de falhas que ocorrem por ano e por unidade de comprimento $(\mathrm{km})$. Já o fator de falhas permanentes expressa a relação entre as falhas permanentes e as totais da rede avaliada.

\section{RESULTADOS DA APLICAÇÃO DA ME- TODOLOGIA BASEADA EM AG}

Para mostrar a aplicabilidade do sistema computacional fundamentado na técnica de AGs são apresentados os resultados de testes obtidos para o sistema elétrico da Fig. 3 e também os indicadores estimados de qualidade de serviço, bem como os seus custos financeiros para cada configuração de instalação de IFs.

\subsection{Resultados para a Alocação de IFs}

A Tabela 1 ilustra os parâmetros iniciais utilizados no AG. Os parâmetros foram aqueles que mostraram melhor desempenho e solução após diversos testes.

Tabela 1: Parmetros empregados.

\begin{tabular}{|c|c|}
\hline Tamanho da Populao & 100 \\
\hline Nmero de Geraes & 100 \\
\hline Elitismo & 0.02 \\
\hline Seleo & Torneio \\
\hline Taxa de Cruzamento & 0.5 \\
\hline Taxa de Mutao & 0.01 \\
\hline Desvio Padro $(\sigma)$ & 2 \\
\hline
\end{tabular}

Na Fig. 12, encontra-se registrado o resultado referente à alocação de um dispositivo IF, para o sistema estudado. O AG encontrou o ponto de instalação situado no tronco principal à $2,13 \mathrm{~km}$ da subestação (barra 85 ). Tal ponto situa-se na área urbana no qual o critério de carga e número de unidades consumidoras é expressivo.

Na Fig. 13, comprova-se a eficiência do AG implementado na alocação de três IFs ao longo do tronco principal. A configuração de instalação dos IF encontrada pelo AG foi de dois pontos localizados na área urbana e um na área rural em atendimento aos critérios delineados na seção 2 .

Na Fig. 14 está ilustrada a configuração encontrada pelo AG para a instalação de sete IFs. Fica evidente que a maior proporção dos IFs a serem instalados situar-se-á em pontos na área urbana, ou seja, no trecho entre a subestação (SE) e a chave religadora $(\mathrm{RL})$.
Pela Fig. 15, é possível observar os resultados da metodologia proposta para alocação de 1 a 10 IFs ao longo do tronco principal em função da distância da subestação. Nota-se que a maioria dos IFs sugeridos se localiza na área urbana devido à concentração de cargas e número de unidades consumidoras nesta região. É possível constatar que o aumento na quantidade de IFs que se deseje instalar apresenta uma mudança em todo o desempenho da resposta do AG. Assim a inserção de um dispositivo adicional não significa que os demais ficarão instalados na mesma posição anteriormente projetada.

\subsection{Estimação dos Indicadores de Quali- dade}

Para avaliação e comparação do desempenho de diferentes configurações de instalação dos IFs, foram estimados os indicadores DEC e END e também os custos financeiros agregados ao emprego desses dispositivos sinalizadores de faltas. Para isso, considerou-se o DEC sem a presença de IFs de 4,8 horas (ANEEL, 2009), $t_{\text {total }}$ de 1 hora, $t_{f}$ de 2 falhas $/ \mathrm{km} / \mathrm{ano}, f_{f}$ de $30 \%$ e fator de carga de 0,7 . Os valores estimados de tempo médio de inspeção despendido pela equipe de plantão, do DEC e da END, estão registrados na Tabela 2. Ressalta-se que não foi considerado o restabelecimento do sistema por meio de chaves de socorro nos resultados registrados da Tabela 2. Os tempos envolvidos no cál-

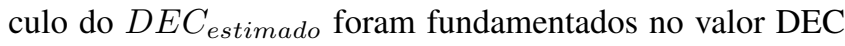
padrão da ANEEL, exceto o tempo médio despendido pelas equipes de plantão para encontrar o ponto defeituoso, conforme ilustrado na seção 4.2.

Por meio dos resultados estimados de DEC e END, podese comprovar que a inserção dos IFs em posições do tronco sugeridos pelo AG reduz tais indicadores.

\subsection{Avaliação dos Custos Financeiros}

De posse das configurações de instalação de IFs que se deseje instalar e também dos indicadores de desempenho estimados, necessita-se apurar os custos financeiros para cada quantidade de IFs. Para isso, alguns aspectos financeiros foram considerados e estimados.

Primeiramente, é necessário apurar os custos de interrupção não programada, em Reais (R\$), conforme a expressão (18). Para tais custos, adota-se a END definida pela equação (17).

$$
\text { Custo }_{\text {interrupo }}=E N D_{\text {estimado }} \cdot \text { Tarif }_{\text {mdia }}
$$

onde Tarif $a_{m d i a}$ representa a tarifa média em $\mathrm{R} \$ / \mathrm{kWh}$. 


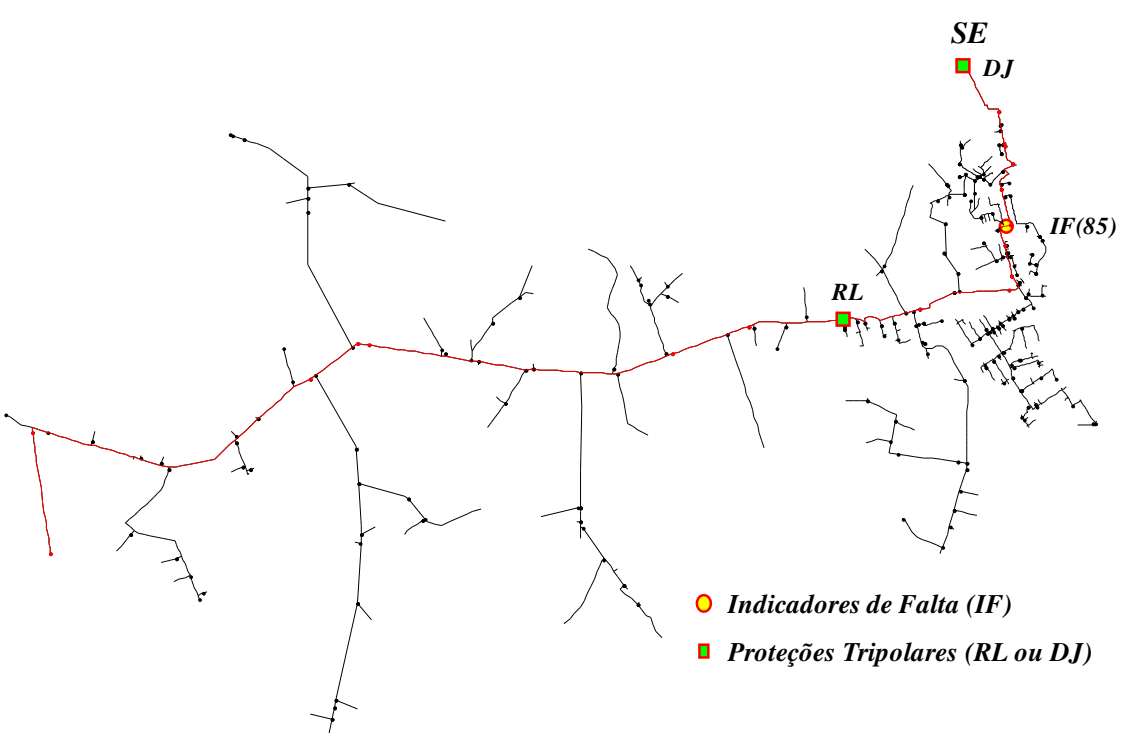

Figura 12: Alocação de 1 IF no tronco principal.

Tabela 2: Parmetros empregados.

\begin{tabular}{|c|c|c|c|}
\hline $\begin{array}{c}\text { No } \\
\text { IFs }\end{array}$ & $\begin{array}{c}\text { Tempo } \\
\text { médio de } \\
\text { inspeção (h) }\end{array}$ & $\begin{array}{c}\text { DEC } \\
\text { estimado } \\
\text { (h/ano) }\end{array}$ & $\begin{array}{c}\text { END } \\
\text { estimado } \\
\text { (MWh/ano) }\end{array}$ \\
\hline 0 & 0,37 & 4,80 & 49,46 \\
\hline 1 & 0,32 & 3,84 & 39,57 \\
\hline 2 & 0,27 & 3,36 & 34,62 \\
\hline 3 & 0,25 & 3,07 & 31,65 \\
\hline 4 & 0,23 & 2,88 & 29,68 \\
\hline 5 & 0,22 & 2,74 & 28,26 \\
\hline 6 & 0,21 & 2,64 & 27,20 \\
\hline 7 & 0,25 & 2,56 & 26,38 \\
\hline 8 & 0,24 & 2,49 & 25,72 \\
\hline 9 & 0,23 & 2,44 & 25,18 \\
\hline 10 & 0,23 & 2,40 & 24,73 \\
\hline
\end{tabular}

Outro custo relevante nesta análise refere-se ao custo do IF em Reais por ano (R\$/ano), sendo expresso pela equação (19).

$$
\text { Custo }_{I F}=\frac{V N_{I F}+C I_{I F}}{V U_{I F}}+C M_{I F}
$$

onde $V N_{I F}$ representa o valor de um novo IF em $\mathrm{R} \$, C I_{I F}$ é o custo de instalação de um IF em $\mathrm{R} \$, V U_{I F}$ é a vida útil em anos e o $C M_{I F}$ é o Custo de Manutenção de um IF.
A Tabela 3 apresenta os custos referentes à operação de um IF nos sistemas de distribuição, segundo informações fornecidas pela empresa que administra o alimentador, foco desta pesquisa.

Tabela 3: Custos do IF.

\begin{tabular}{|c|c|}
\hline Custos & R\$ \\
\hline Novo IF Monofásico $\left(V N_{I F}\right)$ & 2000,00 \\
\hline Instalação $\left(C I_{I F}\right)$ & $5 \% V N_{I F}$ \\
\hline Manutenção $\left(C M_{I F}\right)$ & $5 \% V N_{I F}$ \\
\hline Vida Útil $\left(V U_{I F}\right)$ & 8 anos \\
\hline
\end{tabular}

Por meio dos custos da Tabela 3 agregados à expressão (19), obtém-se o custo de instalação de um dispositivo IF em $\mathrm{R} \$$ /ano. Considerando o valor da tarifa média residencial, homologada pela ANEEL em 2008, como R \$ 0,33384/kWh e os valores de END da Tabela 2, tem-se a estimativa do custo de interrupção (ANEEL, 2008b). Cabe ressaltar que os custos para restabelecimento do sistema, como, por exemplo, custos da equipe de manutenção e centros de operação, foram desprezados uma vez que tais custos no Brasil são reconhecidos no modelo de empresa de referência regulatório (ANEEL, 2008a).

Em conclusão, na Tabela 4 estão registrados os custos estimados para cada uma das configurações de IFs proposta pelo AG. Por meio da mesma, verifica-se que as estimativas dos custos financeiros apontam a viabilidade da aplicação de dispositivos IFs, pois os investimentos necessários ao seu emprego são inferiores quando comparados com os custos das 


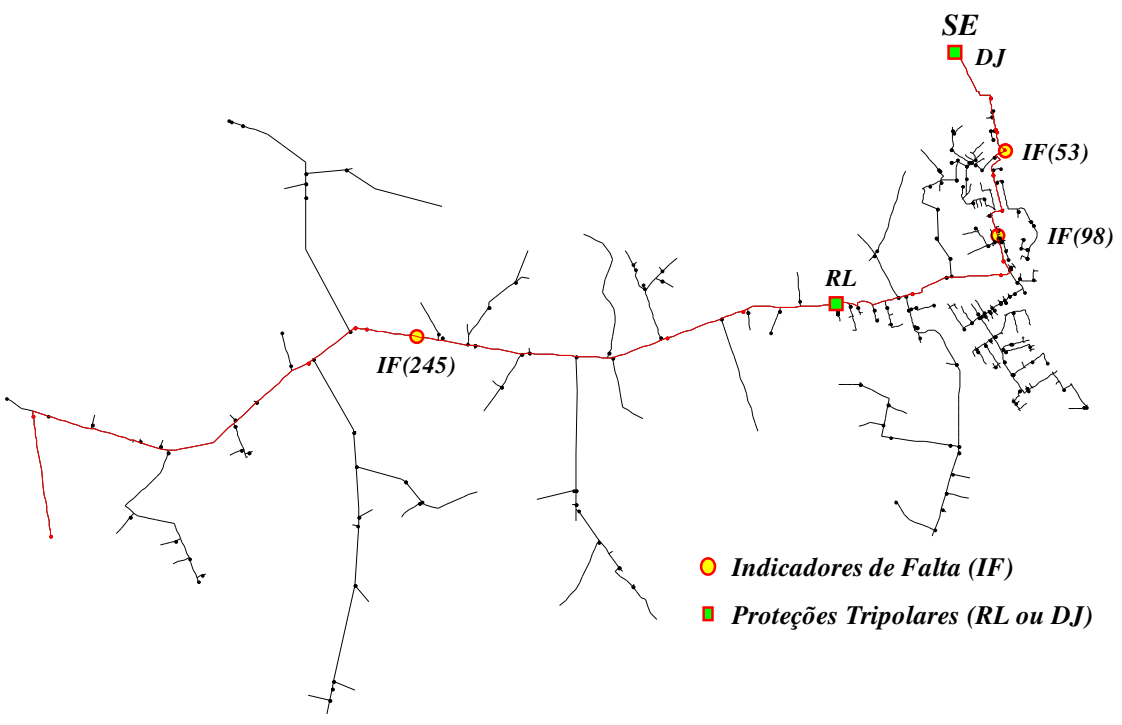

Figura 13: Alocação de 3 IFs no tronco principal.

Tabela 4: Estimativas de custos financeiros para cada configurao de IFs.

\begin{tabular}{|c|c|c|}
\hline $\begin{array}{c}\text { No } \\
\text { IFs }\end{array}$ & $\begin{array}{c}\text { Custo Estimado de } \\
\text { Interrupo (R\$/ano) }\end{array}$ & $\begin{array}{c}\text { Custo Estimado do IF } \\
\text { (R\$/ano) }\end{array}$ \\
\hline 0 & $16.511,46$ & - \\
\hline 1 & $13.209,17$ & $1.087,50$ \\
\hline 2 & $11.558,02$ & $2.175,00$ \\
\hline 3 & $10.567,33$ & $3.262,50$ \\
\hline 4 & $9.906,88$ & $4.350,00$ \\
\hline 5 & $9.435,12$ & $5,437,50$ \\
\hline 6 & $9.081,30$ & $6.525,00$ \\
\hline 7 & $8.806,11$ & $7.612,50$ \\
\hline 8 & $8.585,96$ & $8.700,00$ \\
\hline 9 & $8.405,83$ & $9.787,50$ \\
\hline 10 & $8.255,73$ & $10.875,00$ \\
\hline
\end{tabular}

perdas de energia não distribuída devido a desligamentos permanentes, exceto nas configurações de 8,9 e 10 IFs.

Como exemplo, tem-se o custo da energia não distribuída devido a desligamentos, sem a presença de IFs, de R\$ 16.511,46. Estima-se que um investimento estimado de $\mathrm{R} \$$ 1.087,50 ao ano com a instalação de um IF reduza os custos anuais de interrupção para R\$13.209,17.

Diante das análises citadas, pode-se constatar a total coerência da resposta do sistema proposto de alocação de IFs funda- mentado na técnica de AG. Os resultados fornecidos pelo sistema inteligente foram gerados de forma automática e sem a necessidade de mão de obra especialista. Tendo em vista sistemas com muitos alimentadores e grandes extensões, como, por exemplo, os encontrados no Brasil, ficam evidentes os benefícios da ferramenta inteligente na busca das melhores posições para a instalação de IFs, uma vez que os resultados são obtidos de forma automática.

\section{CONCLUSÕES}

Este artigo apresentou uma estratégia eficiente para alocação de IFs em alimentadores de distribuição por meio de técnicas de AGs. Este trouxe contribuições como a definição de critérios objetivos para a alocação de IFs e o desenvolvimento de uma técnica que permitiu avaliar a proximidade de IFs entre si, como também em relação a equipamentos de proteção com função de indicação de falta.

Ressalta-se que os estudos foram motivados pela necessidade, por parte das empresas distribuidoras de energia, de possuir uma metodologia de alocação eficiente dos dispositivos IFs que pudesse ser automatizada e utilizada de forma genérica em qualquer alimentador.

Os objetivos principais deste trabalho foram alcançados, tendo em vista que os resultados obtidos foram extremamente coerentes com as pertinências das variáveis delineadas nas seções anteriores, uma vez que sempre foram empregadas informações reais do alimentador foco do estudo. Especificamente, a metodologia fundamentada em AG demonstrou eficiência e robustez em encontrar boas configurações 


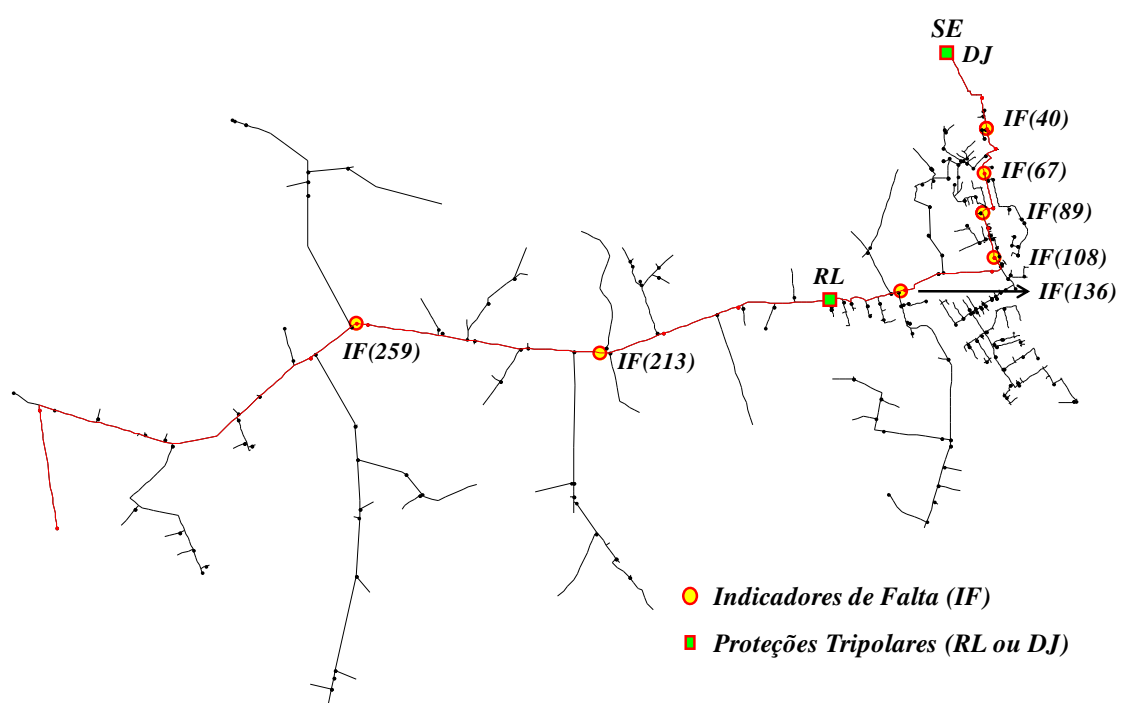

Figura 14: Alocação de 7 IFs no tronco principal.

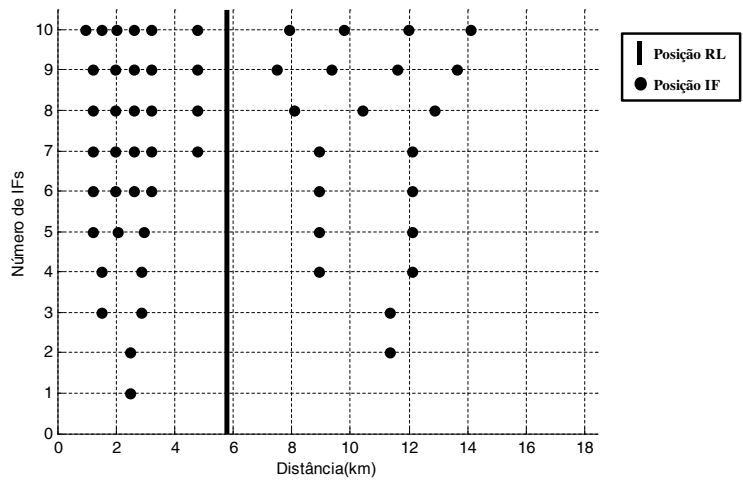

Figura 15: Posicionamento dos IFs no tronco principal.

de instalação de IFs principalmente em grandes espaços de busca.

Os resultados registrados na Fig. 15 e Tabelas 2 e 4 permitem ao projetista comparar os ganhos entre configurações de instalação com diferentes quantidades de IFs e, ponderar o benefício obtido de cada configuração em contrapartida ao investimento necessário.

Adicionalmente, em áreas de concessão de grandes proporções e inúmeros alimentadores de distribuição, ficam evidentes os benefícios deste trabalho na busca das melhores posições para a instalação de IFs, pois os resultados são obtidos de forma automática, permitindo reduzir imensamente a quantidade de horas de engenharia necessárias para alocação de IFs.
Cabe ressaltar que as configurações aqui obtidas não atendem a todos os critérios reais que envolvem a instalação dos IFs, visto que há obstáculos naturais que impossibilitam atender plenamente o posicionamento sugerido pelo AG. No entanto, o emprego de AG mostrou-se bem apropriado na obtenção de configurações eficientes de instalação de IFs para melhoria da qualidade do serviço prestado pelas distribuidoras de energia elétrica.

\section{AGRADECIMENTOS}

Os autores agradecem ao CNPq - Conselho Nacional de Desenvolvimento Científico e Tecnológico, MSc. Danilo H. Spatti e também aos profissionais Eng. Msc. Debora M.B.S. de Souza, Eng. MSc. Valmir Ziolkwoski e Adelcio F. Assis da empresa ELEKTRO. 


\section{REFERÊNCIAS}

ANEEL (2008a). Agncia nacional de energia eltrica - resoluo normativa $\mathrm{n}^{o} 338$ - estabelece metodologias aplicveis e os procedimentos iniciais para realizao do $2^{\circ}$ ciclo de reviso tarifria., Disponível em http://www . aneel.gov.br/biblioteca.cfm.

ANEEL (2008b). Agncia nacional de energia eltrica - tarifas residenciais vigentes, Disponível em http: / / www . aneel.gov.br/area. cfm? idArea $=493 \& i d P \operatorname{erfil}=2$.

ANEEL (2009). Agncia nacional de energia eltrica - procedimentos de distribuio, Disponível em http : / / www . aneel.gov.br/82.htm.

Baldwin, T., Renovich, F., J. and Saunders, L. (2003). Directional ground-fault indicator for high-resistance grounded systems, IEEE Transactions on Industry Applications 39(2): 325-332.

Baldwin, T., Renovich, F., J., Saunders, L. and Lubkeman, D. (2001). Fault locating in ungrounded and highresistance grounded systems, IEEE Transactions on Industry Applications 37(4): 1152-1159.

Cong, D.-P., Raison, B., Rognon, J.-P., Bonnoit, S. and Manjal, B. (2005). Optimization of fault indicators placement with dispersed generation insertion, IEEE Power Engineering Society General Meeting, 2005., Vol. 1, pp. 355-362.

de Souza, D., de Assis, A., da Silva, I. and Usida, W. (2008). Efficient fuzzy approach for allocating fault indicators in power distribution lines, IEEE/PES Transmission and Distribution Conference and Exposition: Latin America, 2008, pp. 1-6.
Falaghi, H., Haghifam, M.-R. and Tabrizi, M. R. O. (2005). Fault indicators effects on distribution reliability indices, 18th International Conference and Exhibition on Electricity Distribution, 2005. CIRED 2005., pp. 1-4.

Haupt, L. and Haupt, S. (2004). Practical Genetic Algorithms, 2 edn, Wiley.

Kagan, N., de Oliveira, C. and Robba, E. (2005). Introduo a Sistemas de Distribuio de Energia Eltrica, Editora Edgar Blucher. pp. 279-305.

Kagan, N., Robba, E. and Schmidt, H. (2009). Estimao de Indicadores de Qualidade de Energia Eltrica, Editora Edgar Blucher. pp. 11-77.

Kersting, W. (1991). Radial distribution test feeders, IEEE Transactions on Power Systems 6(3): 975-985.

Krajnak, D. (2000). Faulted circuit indicators and system reliability, Rural Electric Power Conference, 2000, pp. A4/1-A4/4.

Muench, F. and Wright, G. (1984). Fault indicators: Types, strengths applications, IEEE Transactions on Power Apparatus and Systems PAS-103(12): 3688-3693.

Tang, Y., Wang, H., Aggarwal, R. and Johns, A. (2000). Fault indicators in transmission and distribution systems, International Conference on Electric Utility Deregulation and Restructuring and Power Technologies, 2000. Proceedings. DRPT 2000., pp. 238-243.

Zhang, H., Pan, Z. and Sang, Z. (2004). Fault locating in ungrounded and compensated systems, Eighth IEE International Conference on Developments in Power System Protection, 2004., Vol. 2, pp. 469-472. 